\title{
Socio Linguistic Study of Code Switching of the Arabic Language Speakers on Social Networking
}

\author{
Ahmad Abdel Tawwab Sharaf Eldin ${ }^{1}$ \\ ${ }^{1}$ Wake Forest University, Department of Romance Languages, Winston Salem, North Carolina, USA \\ Correspondence: Ahmad Abdel Tawwab Sharaf Eldin, Department of Romance Languages, Wake Forest \\ University, North Carolina, USA. E-mail: brave107@yahoo.com
}

\author{
Received: October 11, 2014 Accepted: November 2, 2014 Online Published: November 25, 2014 \\ doi:10.5539/ijel.v4n6p78 URL: http://dx.doi.org/10.5539/ijel.v4n6p78
}

\begin{abstract}
Researches on code-switching in the past have a concentration on the verbal language, few on its written form. This study attempts to cover and analyze the notion of code-switching in electronic contexts. The objective of this study is to discuss the code-switching functions performed by Arabic-English bilingual users in their Facebook interactions. The data of this study were collected from status updates posted by the bilingual users on their Facebook wall. They were classified and analyzed according to the functions they served in the Facebook context. Findings indicate that code switching occurs in online interaction to serve addressee specification, reiteration, message qualification, clarification, emphasis, checking, indicating emotions, availability, principle of economy and free switching functions. This study hopes to provide insights on the code-switching phenomenon in Computer-Mediated Communication (CMC). Additionally, the findings of this study will be of value for the development of code-switching studies in the socio linguistic area.
\end{abstract}

Keywords: code switching, sociolinguistics, CMC, Facebook, bilingualism

\section{Introduction}

Ever since the idea of its existence, the concept of code-switching has influenced and encouraged the emergence of various research areas that are highly relevant in the field of Bilingualism. Educators have looked into areas related to the types of code-switching and its social roles, the different patterns of code-switching amongst children and adults, as well as the different reasons that encourage the occurrence of code-switching in speech. All these different studies and researches have also suggested various definitions to what code-switching can be referred to. Code-switching could be defined as a term used to refer to the act of conversing in another language, besides the mother tongue. On the other hand, code-switching is also defined as a combination of words, phrases and sentences that result from sentence limitations in similar speech context. Based on these definitions, it can be deduced that code-switching in general can be regarded as the act of speaking in different languages interchangeably in order to overcome language constraints, to deliver speeches effectively and most importantly as a crucial step towards achieving successful communication.

\subsection{Theoretical Background}

A person is said to be multilingual if he or she is competent in more than one language. Multilingualism is usually the result of many factors, such as colonisation, intercultural marriage, cultural interaction, education, and many other reasons. The applied linguist Del Hymes (1979:30) defines communicative linguistic competence as, '[a person] acquires competence as to when to speak, when not, and as to what to talk about with whom, when, where, in what manner' (Hymes, 1979). In this way, a person who is capable of using appropriately two languages or more is said to be multilingual. Usually, bilinguals and multilinguals tend to switch languages within the same utterance. This phenomenon is referred to as code-switching. Eyamba Bokamba, a professor of Second Language Acquisition at the University of Illinois defines code-switching as, "the mixing of words, phrases and sentences from two distinct grammatical (sub) systems across sentence boundaries within the same speech event" (Bokamba, 1989:12). Code-switching is then one phenomenon that results from bilingualism and multilingualism. Sociolinguists have always been interested in studying the phenomenon and the reasons that stand behind it. There are many factors that stand behind code-switching, like solidarity, social status, topic, affection, and persuasion. The main body of the paper is divided into three parts. The first part of the body sets the definition of the 
phenomenon of code-switching. The second paragraph highlights five reasons that lead to code-switching while the third paragraph contains the conclusion of the paper.

\subsection{Objectives of the Study}

The primary objective of this study is to examine the phenomenon of code-switching in computer-mediated communication by bilingual university students. The various reasons for code-switching are identified by collecting and analyzing students' bilingual texts in social-networking website which has been a popular medium of communication on the Internet.

\subsection{Significance of the Study}

This study will add to the existing literature on code-switching, specifically on online conversation. Information gained from the study will help to provide insight on how and why code-switching occurs not only in spoken but also in written form. It is important as bilinguals will then be aware of the code-switching that occurs during online communication via social networking website. As a result, code-switching can be used to obtain positive effects in online conversation by bilinguals such as to express group solidarity, establish goodwill and emphasize a point as mentioned by Muthusamy (2009).

\subsection{Research Questions}

The research questions for this study are as follows:

1) What are the reasons for Arabic English bilingual students to switch codes in online messages sent via social networking websites such as Facebook?

2) What are the effects for the phenomenon of code-switching among Egyptian Arabic -English bilingual students in social networking website?

\subsection{Literature Review}

The convergence of the Internet and the web has brought about a new medium for information sharing and communication known as computer-mediated communication (CMC). Crystal (2006) used the term Internet linguistics to refer to the study of the new styles and formats and the development of language that emerged from the new electronic media. According to Thurlow, Lengel and Tomic (2004), CMC fundamentally refers to any human communication achieved through, or with the help of computer technology. The areas include all types of Internet activity such as e-mail, instant messaging, games interaction and bulletin boards. Crystal (2006) views $\mathrm{CMC}$ as an emerging third medium, a hybrid between traditional speech and writing where certain properties are shared by $\mathrm{CMC}$ while others are not. The trending usage of CMC is indeed imposing different conditions for language to be used than those by other forms of conventional communication. Studies have shown contradicting results of how language is used in CMC. Therefore, the change in code-switching can also be traced from the language of the swiftly developing medium of communication.

\section{Code-Switching Definition}

In many situations, a speaker may shift from one code to another, intentionally or unintentionally. This shift may be from one language to another, from one dialect to another, or from one style to another for many different reasons. A bilingual teacher in class may switch his or her language in order to elaborate a certain point they are explaining. Sociolinguists refer to this shift as 'code-switching'. Joan Swann and Indra Sinka explain that 'definitions of codes-witching vary' (Swann \& Sinka, 2007). Indeed, the definition of code-switching varies from one linguist to another, thus I will use several definitions that were set by various sociolinguists. It must be noted that I have highlighted that any person who is capable of switching codes must be a competent bilingual or multilingual. Thus, despite the different definitions of code-switching that I will introduce, linguistic competence should always present. In the book Discourse Strategy, John J. Gumperz defines what he calls 'conversational code-switching' as 'the juxtaposition within the same speech exchange of passages of speech belonging to two different grammatical systems or subsystems. ... as when a speaker uses a second language either to reiterate his message or to reply to someone else's statement' (Gumperz, 1982). Another approach to defining code-switching was set by sociolinguist Kathryn Woolard. She defines code-switching as 'the investigation of an individual's use of two or more language varieties in the same speech event or exchange' (Woolard, 2004). Thus, as I have previously discussed in the introduction, code-switching occurs within the same single utterance. The term 'code-switching' differs from other language interaction phenomena, such as lexical borrowing. Lexical borrowing is the result of lack of a lexical terms in the speakers repertoire while in code-switching, as Janet Holmes says, speakers have a genuine choice 


\section{Reasons for Code-Switching}

As I have mentioned, in this part, I will be discussing the reasons why people switch codes. Speakers may switch from one code to another either to show solidarity with a social group, to distinguish oneself, to participate in social encounters, to discuss a certain topic, to express feelings and affections, or to impress and persuade the audience.

\subsection{To Show Solidarity}

Janet Holmes mentions in her book Introduction to Sociolinguistics that, 'a speaker may. . . switch to another language as a signal of group membership and shared ethnicity within an addressee' (Holmes, 2000). Code-switching can be used to express solidarity between people from different or the same ethnic groups.

\subsection{To Reflect Social Status}

Sometimes, speakers tend to use different languages to imply a certain social status or to distinguish themselves from other social classes. Other reasons that have been found to motivate CS are to sound elitist or classy. Professor Peter Auer says in his book Code Switching in Conversation: Language, Interaction and Identity that 'Code-switching carries a hidden prestige which is made explicit by attitudes' (Auer, 2002). Also, Dr Hayat Al Khatib says in a research she conducted that speakers may use code-switching 'to show power over the less powerful' (Al-Khatib, 2003) Thus, I can now connect switching codes as a way to reflect one's social class. A speaker who can code-switch implies that he is a well educated person who is competent in two languages or even more. Thus, code-switching can be looked upon as a way to distinguish oneself. Yasir Suleiman says that, 'the phenomenon of CS is very common and is looked upon as something prestigious and a sign of education and competence in more than one language' (Suleiman, 1999).

\subsection{Topic}

Topic, on another hand, seems to be another important reason that leads a bilingual speaker to code-switch. Janet Holmes says on the issue of code-switching according to the topic when she says, "people may switch code within a speech event to discuss a particular topic' (Holmes, 2000). Thus, speakers may tend to use more than one language within one same utterance according to the topic. In many situations, a bilingual may tend to talk about one certain topic in a language rather than another. Another good example can be one from the Lebanese society. Discussing emotional and sexual topics in the Lebanese community is 'easier' when it is discussed in a language that is different than the native Arabic language of the society. 'Taboo words and topics are often codes-witched so as to avoid to be expressed in the speaker's native language' (Leung, 2006). Speakers in the Lebanese society tend to discuss sexual topics and emotional topics in English or French since it will make them more comfortable to discuss those issues which have always been labelled as 'taboos' in a language different than their community's one. In a study by Khalid M. Abalhassan from the University of Indiana and Hamdan G. Al Shalawi from Arizona State University, they collected data from twelve bilingual Arabic speaking students in order to answer " 'why did you code-switch to English language'?'. Although the answers were different in the result, one of the twelve students replies, which grabbed my attention, was because 'I can't say taboo words in Arabic' (Abalhassan \& Al Shalawi, 2000).

\subsection{Affection}

Code-switching can be used by speakers to express certain feelings and attitudes. Speakers may switch codes to express happiness, excitement, anger, sadness, and many other feelings. Why do People Code-switch? Janet Holmes says, 'A language switch . . . is often used to express disapproval. So a person may code switch because they are angry. Dr. Hayat Al-Khatib gives an example in the same research mentioned above about code-switching to express feelings. 'After asking nicely for a piece of paper from her brother's pad, to not avail, A attempts to snatch a paper from his jotting pad "did I say ey did I say ey? When I say ey it means ey, when I say la' it means la')' (Al-Khatib, 2003). In the example provided by Al-Khatib, the speaker uses more than one language to express anger and dissatisfaction. Janet Holmes also gives another good example about code-switching to express affection. 'In the town of Oberwart two little Hungarian-speaking children were playing in the woodshed and knocked over a carefully stacked pile of firewood. Their grandfather walked in and said in Hungarian.

'Szo!idedzuni! jesztjeramunyi mind e kettutoko, no hat akkor!'

[Well Come Here! Put All This Away, Both of You, Well Now.]

When they did not respond quickly enough he switched to German: 'Kum her!' [Come Here] (Holmes, 2000). In the above example, the Grandfather used the German language to express a more straight and angry attitude to express his anger of the behaviour of the children. 


\subsection{To Persuade Audience}

Janet Holmes defines the term metaphorical switching as, 'code-switching for rhetorical reasons' (Holmes, 2000). Code-switching is often used in speech and rhetoric, on purpose in order to either attract attention and to persuade an audience. Adina Nerghes comments on the effect of code-switching in persuasion and its ability to grab the attention of the audience by saying, 'code-switching will draw the participant's attention and will enhance their motivation to carefully scrutinize the message presented' (Nerghes, 2011). When a speaker uses code switching in persuasion and rhetoric, they will be more capable of reaching their goal and in persuading their audience since as I have mentioned, code-switching grabs attention, and reflects a certain socioeconomic identity which can give the speaker more credibility and reliability. As Nerghes concludes in her study, she says that 'It is concluded that code-switching is an effective strategy that leads to systematic processing of information especially when associated with strong arguments' (Nerghes, 2011).

\section{Facebook}

Facebook is a social network website that provides an extensive number of features for its users to socialize and share information about themselves. Users can sign up on the website with a valid e-mail address and create a profile page, allowing them to keep updated with friends' social activities, upload photos, share links and videos and connect with people. As of January 2011, the network was estimated to have more than 600 million monthly active users worldwide (Carlson, 2011). One of the main features is the News Feed where users can publish status updates and share them with users in their network. The status updates posted on users' profiles pages will then available to be replied or commented on at any time by other users. Thus, Facebook has become the leading social network platform on the Internet and a vital communication tool globally.

\section{Bilingualism and Code Switching}

Bilingualism is a concept often associated with code-switching as a speaker must be able to perform more than a language in order to code switch. Numerous attempts have been made by linguists to describe and fully understand the concept from various aspects such as categories, factors and degree of bilingualism.

One of the earliest studies carried out by Bloomfield (1933) broadly defined bilingualism as the "native-like control of two languages." The definition raised some questions on the degree of mastery or competency of a speaker in the languages in order to be considered to have native like control.

Haugen (1953) further explained that bilingualism only exists when a speaker of one language has the ability to produce complete meaningful utterances in another language. While the definitions remain vague and do not entirely reveal what exactly is needed for a speaker to be a bilingual, both Weinreich (1953) and Mackey (1957) provided a more or less similar definition where bilingualism is said to be the alternate use of two languages or more by the same speaker, altogether embracing the concept of multilingualism in its definition.

\subsection{Code and Code-Switching}

The concept of code refers to any system of signals, such as numbers, words, signal, which carries concrete meaning. The term code is a neutral term rather than terms such as dialect, language, style, which are inclined to arouse emotions. Code can be used to refer to any kind of system that two or more people employ for communication. When a particular code is decided on, there is no need to stick to it all the time. People can and should shift, as the need arises, from one code to another .In the studies of code-switching, there have been various definitions of the term "code-switching".

Gumperz referred to it as "the juxtaposition within the same speech exchange of passages of speech belonging to two different grammatical systems or subsystems" (p.59). Cook came up with the notion that code-switching is the process of "going from one language to the other in mid-speech when both speakers know the same languages" (p.83). It is the systematic alternating use of two languages or language varieties within a single conversation or utterance. To be brief, code-switching is the shift from one language to another within a conversation or utterance. In the context of foreign language classroom, it refers to the alternate use of the first language and the target language, a means of communication by language teachers when the need arises.

\subsection{Types of Code-Switching}

There have been many attempts to give a typological framework to the phenomenon of code-switching. One of the most frequently discussed is that given by Poplack (1980). Poplack (1980) identified three different types of switching which, more often than not, bilinguals will find themselves switching or mixing between languages that they are familiar with regularly while engaging in a conversation daily. Known as code-switching in linguistics, many bilinguals will utilize their ability to shift from one language to another to communicate with others in an 
unchanged setting and usually within the same utterance (Bullock \& Toribio, 2009). Code-switching is traditionally assumed to be an indication of language knowledge deficiency in bilingual speakers. However, various researchers have proposed that code-switching is also commonly used by bilinguals to achieve particular interactional goals in a conversation with other speakers (Shin, 2010).

Additionally, code-switching was viewed as a choice in determining the linguistic choices used in a conversation where the rewards and costs for using either of the languages was weighed by the switcher to achieve a particular outcome (Myers-Scotton, 1979).

The theory was further represented in Myers-Scotton's (1993) Markedness Model based on the social motivation of code-switching. The model centers on the notion of code-switching as low level proficiency in the second language . The model centers on the notion of code-switching as language choices made by speakers and it is seen as either an unmarked or marked language choice in different speech situations. Code-switching is deemed as an unmarked or safe choice when it is more or less expected in a particular type of interaction that is determined by factors other than the conversation content such as social and situational settings. In contrast, marked choice is unpredictable, disregarding social and situational factors and what is expected in the interaction. Therefore, a marked choice is a negotiation about the speaker and the speaker's relationship with other participants (Myers-Scotton, 1993). In one of the early researches, Bloom and Gumperz (1972) identified two types of code-switching: situational and metaphorical. Situational code switching is influenced by situation change in a conversation or discourse such as the change in participant, topic or setting. Metaphorical or conversational code-switching, on the other hand, works as a conversational strategy to assist conversational acts such as an apology, request, complaint or refusal. From another perspective, Poplack (1980) categorized code-switching into the following three types: tag-switching, intersentential and intrasentential.

\subsection{Tag-Switching}

Tag-switching involves inserting a tag or short phrase in one language into an utterance that is otherwise entirely in another language. This type of code-switching occurs the most easily for the reason being that tags typically contain minimal syntactic restrictions thus not violating syntactic rules when being inserted into monolingual sentences. Common English tags such as I mean, you know and I wish are some of the examples that fit into that category.

\subsection{Inter-Sentential Switching}

Intersentential switching happens at clausal or sentential level where each clause or sentence is in one language or another. Occurring within the same sentence or between speaker turns, this type of code-switching requires its speaker to be fluent in both languages in order to conform to the rules of the languages.

\subsection{Intra-Sentential Switching}

Intra-sentential switching is possibly the most complex type among the three, can take place at clausal, sentential or even word level Since the early 1970s, code-switching has gained the interest of scholars as a naturally occurring use of languages by bilinguals (Ariffin\&Rafik-Galea, 2009). The motivations, functions and reasons of code-switching have been studied extensively by a number of researchers from various linguistics perspectives.

Malik (1994) in discussing the sociolinguistics of code-switching of the language situation in India explained ten reasons for speakers to code-switch.

\section{Framework for This Paper}

In this research, the researcher attempts to focus on code switching in a social network between speakers of Arabic and English Malik's (1994) review on ten reasons for code-switching will be used to discuss the occurrences of code-switching in online communication. The reasons are: lack of facility, lack of registral competence, mood of the speaker, to amplify and emphasize a point, habitual expressions, semantic significance, to show identity with a group, to address different audience, pragmatic reasons and to attract attention.

This framework is used for justifying the phenomenon of code-switching in social-networking website. The framework that is used is as illustrated below: Malik's (1994) ten reasons for code-switching

* Lack of facility

* Lack of competence

* Semantic significance

* To address different audience

* To show identity with a group 
* To amplify and emphasize a point

* Mood of the speaker

* Habitual expressions

* Pragmatic reasons

* To attract attention

\subsection{Lack of Facility}

According to Malik (1994), bilinguals or multilinguals often explain that they code switch when they cannot find an appropriate expression or vocabulary item or when the language of conversation does not have the particular word needed to carry on the conversation smoothly. The reason for switching may however be culturally conditioned and an alien concept often has a speaker switch to the language from which the concept is borrowed. According to Malik (1994) affirms that that the participant couldn't find an appropriate expression or vocabulary item in Arabic at that moment of conversation, and that is why lack of facility could be of the reasons. For instance,

"eh elkhbar ya man" "what is up, man?"

In this example speaker obviously does not have English word for "eh elkhbar" so here switching is culturally conditioned.

\subsection{Lack of Register}

When speakers are not equally competent in two languages and when the speakers do not know the terms in two languages, then code-switching occurs. For example, in certain occupations code switching takes place in the speech of doctors, lawyers, engineers while they interact among themselves owing to the fact that proper terms in Arabic or in any other language other than English may not be available to them. As a result, they utilize the English terminology that they are familiar with. For example, "ha ?amlserjiiry" "I will make the surgery"

\subsection{Mood of the Speaker}

Malik (1994) claims that usually when bilinguals are tired or angry, code switching takes place with a new dimension. This means, when the speaker is in the right state of mind, he/she can find the appropriate word or expression in the base language. Very often he/she knows exactly the word in both the languages, but the native language may be more available at the point of time when the speaker has a disturbed mind. Such circumstances may create a hurdle in getting the appropriate word or phrase in the language in which the speaker may be more proficient if he is not mentally agitated.

Y: "eh ilmoshkala?" What is wrong?

X: "mosh arfaa, bas I love baba keteer "I do not know, but I love baba kteer

In this conversation $\mathrm{X}$ is speaking to $\mathrm{Y}$ in an angry passionate mood so he switches to English as well in Arabic words, she switches to English.

\subsubsection{Habitual Expression}

Malik.(1994) stresses the fact that code switching often occurs in fixed phrases of greeting and parting, commands and request, invitation, expressions of gratitude and discourse markers such as $\mathrm{O}$, yes (listen) and You know, etc.

"ana hazoor rmasr, you know, we hashoof papa we mama" I will be visiting Egypt, you know, and will see my father and my mother"

\subsubsection{To Emphasize a Point}

Switching is also used to emphasize a point. Gal (1988) reports several instances in which a switch at the end of an argument not only helps to end the interaction but may serve to emphasize a point. She has taken an example from English/German code switching and stressed that switching from English to German is a means of adding more force to the statement.

"SS k test ka w8 karrahahon ...wesykesa test hotahymjy to bht tension hy.........suggest me plzz “

"paperhykaljan mat khaomerykudakawastahy try to understand the concepts "

"kuchkhanykohy to ma aonhstlbhtbhokhy.......dying...."

"lawnprintsbhtpiarythaydilchahasbkharidIonbhtttttpiarythay....really.... . 
In these examples, speakers switch to English at the end of the statement just to add more force in their arguments.

\subsection{Semantic Significance}

Malik (1994) stresses that switching at a particular moment conveys semantically significant information. It is a communicative resource that builds on participant's perception of two languages. Lexical choice conveys meaning during code-switching.

"That tells auntie that $\mathrm{u}$ r a living breathing fiihattanadeefa.

"elanteembetaaiesakanafiishaqaanedeefa"

These examples reinforce Gal's view that listeners interpret code switching as an indicator of the speaker's attitude, or communicative intents and emotions as code switching is a tool for conveying appropriate linguistic and social information. By the same token, David (2003) describes a range of speech acts like reprimands, directives, requests, and warnings that are conveyed by using different intricate strategies to show the semantic significance in certain specific situations.

\subsection{To Show Identity with a Group}

Di Pietro (1977) reports that Italian immigrants would tell a joke in English and give the punch line in Italian, not only because it was better said in Italian but also to stress the fact that they all belong to the same minority group, with shared values and experiences.

In this case, the issue being talked only appeal to those who know what CDA and Bilingualism mean and what is the relationship of the speakers within certain context. Here, the speaker is referring to the English Language topics, Critical Discourse Analysis and Bilingualism and someone relating to these. The end sentences with words like; mashyilhaal and mazboot, also show that the speakers have shared identity of Egyptian and and Levantine.

\subsection{To Address a Different Audience}

Malik (1994) states that code switching is also used when the speaker intends to address people coming from various linguistic backgrounds. For example, in some Egyptian satellite sports channels, the television announcer often uses Modern Standard Arabic as it is the national language but also switches to levantine and gulf dialects as well.

This status given by a Facebook user elaborates this idea clearly that the speaker is addressing different people having different linguistic backgrounds.

Similar types of situations have also been reported in some other settings. One reason for such use of mixed languages is to address simultaneously persons from different linguistic backgrounds. Also, the speaker clearly distinguishes whom he/she addresses and what should be communicated. Hence, the speaker uses part of the sentence in one language and the other part in another language.

\subsection{Pragmatic Reasons}

Sometimes the alternation between two languages is highly meaningful in terms of the conversational context (Malik, 1994). Gumperz (1982) also notes that switching may emphasize varying degrees of speaker's involvement.

"there are other men in the world $u$ knwndjustbecusur 35 does not mean that $u$ wll never ever hv the pleasure of parking ur self on the stage dii “

This statement shows the conversational context where the use of "dii" which means "This" with the idea of 35 year age refers to a specific situation in Egyptian context; so, here switching is consciously made to assert an idea.

\subsection{To Attract Attention}

Malik (1994) shows that in advertisements (in both written as well as in spoken) in India, code-switching is used to attract the attention of the readers/listeners. In English newspapers when the readers come across non-English, either Hindi or any one of the other Indian languages, the reader's attention is automatically drawn to depend on the language background he/she originates from. A similar situation prevails in advertisements that involve audio and video output. In collected data of hundred messages, no example of code switching in order to attract attention, is found as it is only applicable to written and spoken advertisements 


\section{Conclusion}

In this study, the phenomenon of code switching in status and messages posted in social networking site Facebook by Arabic English bilinguals was analyzed by using Malik's ten reasons approach to code switching. this study demonstrates that many of the Facebook users employ code-switching as a tool to enhance their interaction in Facebook. It is also used as a strategy to communicate and negotiate meanings effectively in their electronic discourse. The users' manipulation of both English and Arabic serve them well to achieve both their communicative and stylistic objectives. Therefore, when the users switch due to any of the aforementioned functions, they are suggesting their competence in using both English and Malay. This corresponds to Blom and Gumperz (1972) that code-switching requires speakers to be fully competent in the two languages. Therefore, it can be concluded that code-switching is a natural phenomenon that not only occurs in bilinguals' speech, but also in their electronic discourse. It can be concluded that code switching not only apparent in spoken discourse but also in online written discourse and the reasons for switching codes are similar to those of verbal communication. The study also shows that there are many reasons why code switching takes place in particular social situations. The ability of the interlocutors who are able to speak more than one language fluently plays an important role during their interaction. The study has shown that lack of facility, lack of competence and habitual expressions are the main reason for code-switching. Besides these, mood of the speaker is also another contributing factor for code switching.

\section{References}

Abalhassan, K. M., \& Al Shalawi, H. G. (2000). Code-switching Behavior of Arab Speakers of English as a Second Language in the United States. Intercultural Communication Studies, X(1), 179-188.

Al-Khatib, H. (2003). Language Alternation among Arabic and English Youth Bilinguals: Reflecting or Constructing Social Realities? International Journal of Bilingual Education and Bilingualism, VI(6), 409-422. http://dx.doi.org/10.1080/13670050308667794

Auer, P. (1988). A conversation analytic approach to code-switching and transfer. In Heller, M. (Ed.), Codeswitching: Anthropological and sociolinguistic perspectives (pp. 187-214). Berlin: Mouton de Gruyter. http://dx.doi.org/10.1515/9783110849615.187

Auer, P. (2002). Code-switching in conversation: Language, interaction and identity. New York, NY: Routledge.

Blom, J. P., \& Gumperz, J. J. (1972). Social meaning in linguistic structure: Code-switching in Northern Norway. In J. J. Gumperz \& D. Hymes (Eds.), Directions in sociolinguistics: The ethnography of communication (pp. 407-434). New York, NY: Holt, Rinehart, and Winston.

Bloomfield, L. (1933). Language. New York, NY: Henry Holt.

Bullock, B. E., \& Toribio, A. J. (2009). The Cambridge handbook of linguistic code-switching. New York, NY: Cambridge University Press. http://dx.doi.org/10.1017/CBO9780511576331

Carlson, N. (2011). Facebook has more than 600 million users, Goldman tells clients. The Business Insider.

Crystal, D. (2006). Language and the Internet (2nd ed.). New York, NY: Cambridge University Press. http://dx.doi.org/10.1017/CBO9780511487002

Di Pietro, R. (1977). Codeswitching as a verbal strategy among bilinguals. In F. Eckman (Ed.), Current themes in linguistics: Bilingualism, experimental linguistics and language typologies. Washington, DC: Hemisphere.

Gal, S. (1988). The political economy of code choice. In Heller, M. (Ed.), Codeswitching: Anthropological and sociolinguistic perspectives (pp. 245-264). Berlin: Mouton de Gruyter. http://dx.doi.org/10.1515/9783110849615.245

Gumperz, J. J. (1982). Discourse strategies. New York, NY: Cambridge University Press. http://dx.doi.org/10.1017/CBO9780511611834

Haugen, E. (1953). The Norwegian language in American: A study in bilingual behaviour (Vols. 1-2). Philadelphia, PH: University of Pennsylvania Press.

Holmes, J. (2000). An Introduction to Sociolinguistics (2nd ed.). Wellington: Longman.

Hymes, D. (1979). On communicative competence. In K. Johnson \& C. Brumfit (Eds.), The Communicative Approach to Language Teaching. Oxford: Oxford University Press. 
Leung, C. (2006). Codeswitching in print advertisements in Hong Kong and Sweden. MA Thesis, LundsUniversitet, Linguistics and Phonetics.

Mackey, W. F. (1957). The description of bilingualism. Journal of the Canadian Linguistic Association.

Malik, L. (1994). Socio-linguistics: A study of code-switching. New Delhi, ND: Anmol Publications Pvt. Ltd.

Muthusamy, P. (2009). Communicative functions and reasons for code switching: A Malaysian perspective. Language \& Society, 5.

Myers-Scotton, C. (1979). Codeswitching as a 'safe choice' in choosing a lingua franca. In W. McCormack \& S. Wurm (Eds.), Language and Society (pp. 71-88). The Hauge: Mouton.

Myers-Scotton, C. (1993). Duelling languages: Grammatical structure in code-switching. Oxford: Clarendon.

Nerghes, A. (2011). The Impact of Code-Switching on Persuasion: An Elaboration Likelihood Perspective. Wageningen University.

Poplack, S. (1980). Sometimes I'll start a sentence in Spanish y termino en espanol: Toward a typology of code-switching. Linguistics, 18, 581-618. http://dx.doi.org/10.1515/ling.1980.18.7-8.581

Shin, S. Y. (2010). The functions of code-switching in a Korean Sunday school. Heritage Language Journal, 7(1), 91-116

Suleiman, Y. (1999). Language and society in the Middle East and North Africa: Studies in variation and identity. UK: Curzon Press.

Swann, J., \& Sinka, I. (2007). Style Shifting, Codeswitching.

Thurlow, C., Lengel, L. B., \& Tomic, A. (2004). Computer mediated communication: Social interaction and the Internet. Thousand Oaks, CA: Sage.

Weinreich, U. (1953). Languages in contact: Findings and problems. The Hauge: Mouton.

Woolard, K. (2004). Codeswitching. In A. Duranti (Ed.), A Companion to Linguistic Anthropology (pp. 73-75). Oxford: Blackwell.

\section{Copyrights}

Copyright for this article is retained by the author(s), with first publication rights granted to the journal.

This is an open-access article distributed under the terms and conditions of the Creative Commons Attribution license (http://creativecommons.org/licenses/by/3.0/). 